\title{
ANALISIS PERBANDINGAN KINERJA H-BRIDGE DRIVER MENGGUNAKAN IGBT DAN MOSFET PADA SISTEM KEMUDI STEER BY WIRE
}

\author{
Yusuf Eko Prasetyo ${ }^{1)}$, Fatkhur Rohman ${ }^{2)}$ \\ ${ }^{1)}$ Mahasiswa Program Studi Teknik Otomotif Elektronik Politeknik Negeri Malang \\ ${ }^{2)}$ Dosen Program Studi Teknik Otomotif Elektronik Politeknik Negeri Malang \\ 1)yusufeko217@gmail.com \\ fatkhur_rohman@polinema.ac.id
}

\begin{abstract}
Abstrak
Steer By Wire (SBW) adalah teknologi sistem kemudi terbaru yang menerapkan konsep independen dan full electronic control. Hal ini menyebabkan sistem SBW dapat menghasilkan pengemudian yang lebih responsive, akurat, dan aman bagi pengemudi. Sudah banyak pengembangan dan simulasi untuk membuktikan keunggulan dari sistem kemudi SBW sehingga dapat digunakan disemua kendaraan. Agar dapat merealisasikan sistem ini maka dibutuhkan driver sebagai pengendali motor DC. Saat ini terdapat dua komponen semi konduktor yang sangat populer digunakan sebagai driver yaitu Insulated Gate Bipolar Transistor (IGBT) dan Metal Oxide Semiconductor Field Effect Transistor (MOSFET). Tujuan dari penelitian ini adalah untuk menganalisis dan membandingkan kinerja Motor DC $12 \mathrm{~V}$ sebagai aktuator sistem SBW yang menggunakan driver IGBT dengan driver MOSFET. Metode penelitian yang digunakan adalah analisis kuantitatif komparatif yaitu dengan membandingkan kinerja motor DC $12 \mathrm{~V}$ ketika menggunakan driver IGBT dan ketika menggunakan driver MOSFET. Variabel bebas yang digunakan adalah kecepatan mobil listrik autron dan Beban pengemudi. Sedangkan variabel tetapnya adalah besar sudut belok roda. Hasil dari penelitian ini adalah menyatakan bahwa kinerja motor DC $12 \mathrm{~V}$ lebih baik menggunakan driver MOSFET jika dibandingkan dengan menggunakan driver IGBT.
\end{abstract}

Kata Kunci: Steer by Wire, Motor Driver, IGBT, MOSFET, H-Bridge.

\section{PENDAHULUAN}

Steer by Wire (SBW) adalah teknologi sistem kemudi terbaru yang menerapkan konsep independent dan full electronic controller. Sistem ini dikatakan independent karena tidak ada lagi hubungan langsung antara jalan dengan pengemudi. Hal ini bisa terjadi karena penghubung antara roda kemudi dengan penggerak roda (steering lingkage) tidak lagi menggunakan steering column dan batang kemudi tetapi diganti dengan kabel wiring dan digerakkan oleh motor. Selain menerapkan konsep independen sistem juga menerapkan konsep full eletronic controller. Hal ini bertujuan agar mendapatkan pengemudian yang lebih responsif, akurat, dan aman bagi pengemudi.

SBW memiliki minimal 3 keunggulan jika dibandingkan dengan sistek kemudi terdahulu antara lain, 1) ruang kabin yang lebih luas (Yao, 2006; Kumar, 2012; dan Fahami, 2014) karena tidak terdapat kolom kemudi dan batang kemudi, 2) lebih aman untuk pengemudi (Fahami, dkk. 2014 dan Kaufman, 2001) karena dapat mengurangi benturan dengan komponen-komponen kemudi sehingga mencegah cidera yang berlebihan. 3) rasa pengemudian yang handal untuk manuver dan menghasilkan pengemudian yang mantap (Yao, 2006) karena telah diatur secara full electronic.

Konsep pembuatan SBW pada kendaraan serta cara pengontrolannya telah dijelaskan oleh Yao (2006). Kemudian Fahami (2015) mensimulasikan torsi yang diterim oleh pengemudi pada roda kemudi di kendaraan dengan SBW. Sebelum itu Oh (2004) telah lebih dulu melakukan penelitian bagaimana cara mengatur system 
kemudi saat kendaraan pada kecepatan tinggi dan kecepatan rendah. Hasil dari keseluruhan penelitian memungkinkan untuk membuat dan merealisasikan sistem SBW pada kendaraan.

Pada konsep SBW yang dijelaskan oleh Yao (2006) dan kemudian disimulasikan oleh Fahami (2015) kesemuannya menggunkan 2 motor DC yaitu motor atas (berhubungan dengan roda kemudi) dan motor bawah (berhubungan dengan steering lingkage). Akibat dari penggunaan motor DC maka untuk merealisasikan konsep SBW yang memiliki umpan balik torsi dibutuhkan driver electronik sehingga motor DC bekerja sebagai aktuator dengan baik.

Saat ini terdapat 2 komponen yang sering dijadikan sebagai driver elektronik yaitu 1) Metal Oxide Semiconductor Field Effect Transistor (MOSFET) dan 2) Insulated Gate Bipolar Transistor (IGBT). Kedua komponen ini telah dibahas oleh Blake (2001). Dari penelitian menyatakan bahwa IGBT lebih baik untuk aplikasi diatas 300V sedangkan MOSFET dapat bekerja dengan baik pada tegangan dibawah 300V. Shukla (2017) melakukan perbandingan antara IGBT sebagai inverter untuk motor induksi dengan tegangan diatas 300V. Penelitian ini menyimpulkan bahwa IGBT lebih efisien sebagai inverter motor induksi diatas $300 \mathrm{~V}$ dibandingkan dengan MOSFET.

Dari penelitian diatas menyebutkan bahwa IGBT lebih baik jika dibandingkan dengan MOSFET. tetapi jika diperhatikan penelitian N. K. Shukla dan R. Srivastava (2017) menggunkan motor dengan tegangan diatas 300V. Sehingga diperlukan perbandingan antara MOSFET dan IGBT pada tegangan dibawah $300 \mathrm{~V}$ tepatnya pada tegangan $12 \mathrm{~V}$, karena kendaraan menggunakan baterai $12 \mathrm{~V}$.

Berdasarkan uraian diatas maka dibutuhkan pengujian perbandingan antara IGBT dan MOSFET sebagai driver pada motor DC yang digunakan sebagai aktuator sistem kemudi SBW. Akibat dari tidak adanya sistem SBW di Indonesia maka penyusun akan membuat mobil listrik mini dengan dilengkapi dengan SBW. Oleh sebab itu skripsi dengan judul" Analisis Perbandingan Kinerja Driver H-Bridge Menggunakan IGBT dan MOSFET pada Sistem Kemudi Steer By Wire”.

\section{METODOLOGI PENELITIAN}

Jenis Penelitian yang digunakan adalah analisis kuantitaif komparatif dengan metode uji t satu arah, untuk membuktikan secara statistik terdapat perbedaan atau tidak antara driver motor menggunakan IGBT dan menggunakan MOSFET. Pada penelitian ini digunakan dua variabel bebas dan satu variabel tetap. Variabel bebas yang digunakan adalah massa pengemudi dengan massa $48 \mathrm{Kg}, 65 \mathrm{Kg}, 82 \mathrm{Kg}, 93 \mathrm{Kg}$, dan $128 \mathrm{Kg}$. Variabel bebas yang kedua adalah kecepatan kendaraan listrik yaitu $0 \mathrm{~m} / \mathrm{s}$, $1 \mathrm{~m} / \mathrm{s}, 3 \mathrm{~m} / \mathrm{s}$, dan $5 \mathrm{~m} / \mathrm{s}$. Variabel tetap yang dibaca adalah susut belok kendaraan ketika diperintah berbelok sebesar 15 derajat ke kiri.

Pengambilan dilakukan di lantai 5 gedung Teknik Sipil Politeknik Negeri Malang. Permukaan lantai adalah keramik dan dianggap rata sehingga hambatan dan halangan menanjak dapat diabaikan. Pengambilan data dilakukan dengan cara menjalankan kendaraan sesuia kecepatan kemudian diberikan perintah berbelok sebesar 15 derajat ke kiri. Hasil pembacaan akan ditampilkan ke laptop dengan sambungan serial dengan aplikasi putty. 


\section{HASIL DAN PEMBAHSASAN}

Sistem kemudi ini dapat difungsikan secara manual dan secara otomatis dengan cara menekan saklar pengatur. Cara kerja sistem kemudi ini dimulai dari saklar pengatur mode manual atau mode otomatis, ketika saklar ditombol ke mode manual sistem kemudi akan bekerja seperti biasa dan diatur melalui roda kemudi, tetapi ketika saklar ditekan ke mode otomatis sistem kemudi akan bekerja berdasarkan perintah yang diatur lewat laptop/ potensiometer atau joystick sesuai keinginan. Setelah mendapat perintah dari pengemudi kemudian data diproses pada mikro kontroler unit (MKU). MKU kemudian memerintahkan motor penggerak sistem kemudi untuk bekrja dengan cara memberikan catu daya $5 \mathrm{~V}$ menuju driver motor.

Pada alat ini menggunakan mikrokontroller ATMega32 yang dilengkapi FTDI untuk sambungan serial dengan kabel, dan ESP8266 V.4 yang dapat digunakan untuk hubungan serial cara jauh atau dengan sambungan wifi. Sistem kemudi ini bukan hanya dapat dioperasikan manual dan sistem steer by wire tetapi juga dapat juga sebagai steer by wireless. Hal ini dapat terjadi karena ketika menggunakan sambungan serial dengan ESP8266 V.4 tidak ada lagi sambungan kabel atau komponen mekanik dari sistem pengendali menuju aktuator sistem kemudi.

Pada MKU alat ini terdapat konektor USBASP untuk komunikasi dari laptop menuju MKU sehingga memudahka untuk merubah dan melakukan pembahruan logika penggerakan sistem kemudi. Selain digunakan untuk merubah program port ini juga dapat digunakan sebagai sumber tegangan untuk mengaktifkan MKU, apabila tidak disambungkan ke catu daya $12 \mathrm{~V}$ dari battery. MKU alat ini membutuhkan catu daya $5 \mathrm{~V}$ tetapi baterai yang diggunakan adalah batterai $12 \mathrm{~V}$ sehingga dibutuhkan step down tegangan dari $12 \mathrm{~V}$ ke $5 \mathrm{~V}$ dan yang digunakan adalah LM7805.

Sistem kemudi yang dibuat memiliki 3 cara kerja yaitu 1) manual, 2) steer by wire, dan 3) steer by wireless. Pertama cara kerja manual saat mode manual sistem kemudi bekerja seperti sistem kemudi pada mobil kebanyakan yaitu roda kemudi diputar kemudian tenaga putar diteruskan oleh batang setir ke steering lingkage dan merubah arah kendaraan. Cara kerja kedua adalah cara kerja steer by wire, pada saat mode steer by wire pertama yang dilakukan adalah melepas sambungan ke modul wifi. Setelah itu baru saklar ditekan ke mode otomatis. Ketika mode otomatis roda kemudi tidak bisa digerakkan tetapi harus menggunkan potensiometer atau laptop atau alat lain yang digunakan sebagai inputan besar sudut belok yang diinginkan. Ketika mendapat perintah dari laptop maka sinyal akan dibaca oleh MKU, setalah itu data diproses dan memerintahkan motor yang tersambung pada steering lingkage untuk berkerja dengan cara meberikan catu daya pada motor driver sehingga motor dapat berbelok. Cara kerja terakhir adalah steer by wireless pada saat mode ini cara kerjanya hamper sam dengan cara kerja kedua hanya saja kabel modul wifi harus disambing kembali dan koneksikan sistem inputan ke modul wifi bukan ke FTDI sehingga motor dikendalikan melalui sambungan wifi.

Pengambilan data dilakukan di lantai 5 gedung Teknik Sipil POLINEMA pada malam hari. Obyek yang diteliti adalah sudut belok kendaraan ketika diperintah 15 derajat ke kiri dari PC. Variabel bebas yang digubakan adalah kecepatan kendaraan $(0 \mathrm{~m} / \mathrm{s}, 1 \mathrm{~m} / \mathrm{s}, 3 \mathrm{~m} / \mathrm{s}$, dan $5 \mathrm{~m} / \mathrm{s})$ dan beban penumpang $(48 \mathrm{~kg}, 65 \mathrm{~kg}, 82 \mathrm{~kg}, 93 \mathrm{~kg}$, $108 \mathrm{~kg}$ ). Hasil pengambilan data ditunjukan pada tabel 1 berikut ini. 
Tabel 1. Hasil Pengambilan Data Sudut Belok Kendaraan

\begin{tabular}{|c|c|c|c|c|c|c|c|c|}
\hline \multirow{3}{*}{ 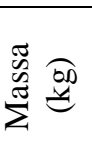 } & \multicolumn{8}{|c|}{ Sudut Belok (derajat) } \\
\hline & \multicolumn{2}{|c|}{$\mathrm{v} 1=0 \mathrm{~m} / \mathrm{s}$} & \multicolumn{2}{|c|}{$\mathrm{v} 2=1 \mathrm{~m} / \mathrm{s}$} & \multicolumn{2}{|c|}{$\mathrm{v} 3=3 \mathrm{~m} / \mathrm{s}$} & \multicolumn{2}{|c|}{$\mathrm{v} 4=5 \mathrm{~m} / \mathrm{s}$} \\
\hline & MOSFET & IGBT & MOSFET & IGBT & MOSFET & IGBT & MOSFET & IGBT \\
\hline \multirow{5}{*}{48} & 14.67 & 3.07 & 14.67 & 12.03 & 14.67 & 9.33 & 14.67 & 10.67 \\
\hline & 14.67 & 3.07 & 14.67 & 12.03 & 14.67 & 12.4 & 14.67 & 10.8 \\
\hline & 14.67 & 2.53 & 14.67 & 11.87 & 14.67 & 8.8 & 14.67 & 10.8 \\
\hline & 14.67 & 2.8 & 14.67 & 11.47 & 14.67 & 9.07 & 14.67 & 11.03 \\
\hline & 14.67 & 2.67 & 14.67 & 11.73 & 14.67 & 10 & 14.67 & 9.93 \\
\hline \multirow{5}{*}{65} & 14.67 & 1.87 & 14.67 & 9.93 & 14.67 & 8.27 & 14.67 & 8.67 \\
\hline & 14.67 & 1.87 & 14.67 & 9.6 & 14.67 & 8.53 & 14.67 & 8.53 \\
\hline & 14.67 & 1.87 & 14.67 & 8.67 & 14.67 & 8 & 14.67 & 8.8 \\
\hline & 14.67 & 2 & 14.67 & 9.07 & 14.67 & 8.93 & 14.67 & 8.57 \\
\hline & 14.67 & 2.13 & 14.67 & 8.53 & 14.67 & 8.93 & 14.67 & 8 \\
\hline \multirow{5}{*}{82} & 11.6 & 1.47 & 14.67 & 2.67 & 14.67 & 1.87 & 14.67 & 2.93 \\
\hline & 10.27 & 1.47 & 14.67 & 2.67 & 14.67 & 2 & 14.67 & 3.2 \\
\hline & 10.27 & 1.47 & 14.67 & 2.67 & 14.67 & 1.87 & 14.67 & 3.07 \\
\hline & 9.73 & 1.6 & 14.67 & 2.8 & 14.67 & 2 & 14.67 & 2.53 \\
\hline & 9.47 & 1.6 & 14.67 & 2.27 & 14.67 & 2 & 14.67 & 3.2 \\
\hline \multirow{5}{*}{93} & 8.53 & 0.8 & 14.67 & 2.67 & 14.67 & 1.33 & 14.67 & 2.27 \\
\hline & 8.53 & 0.93 & 14.67 & 2 & 14.67 & 1.07 & 14.67 & 1.87 \\
\hline & 8.13 & 1.07 & 14.67 & 3.73 & 14.67 & 1.07 & 14.67 & 1.73 \\
\hline & 8.4 & 1.07 & 14.67 & 2 & 14.67 & 1.33 & 14.67 & 1.87 \\
\hline & 8.53 & 1.33 & 14.67 & 1.2 & 14.67 & 1.47 & 14.67 & 1.87 \\
\hline \multirow{5}{*}{108} & 5.87 & 1.07 & 14.67 & 0.93 & 14.67 & 1.2 & 14.67 & 1.73 \\
\hline & 4.93 & 1.2 & 14.67 & 0.8 & 14.67 & 1.33 & 14.67 & 2 \\
\hline & 4.4 & 1.2 & 14.67 & 0.53 & 14.67 & 0.93 & 14.67 & 1.87 \\
\hline & 3.6 & 0.93 & 14.67 & 0.8 & 14.67 & 1.07 & 14.67 & 1.87 \\
\hline & 3.6 & 0.93 & 14.67 & 1.73 & 14.67 & 0.93 & 14.67 & 1.87 \\
\hline
\end{tabular}

Pada Tabel 1 diatas menunjukan hasil pembacaan dari sudut belok kendaraan ketika diperintah untuk berbelok 15 derajat ke kiri. Pada table ini juga menunjukan besar sudut belok kendaraan ketika beban penumpang dan kecepatan kendaraan berubah-ubah. Pada setiap kecepatan terdapat kolom Mosfet dan kolom IGBT hal ini menunjukan sudut belok ketika menggunakan driver Mosfet dan ketika menggunakan driver IGBT. Merujuk dari Tabel 1 yang berkaitan dengan IGBT dapat diambil ratarata setiap perlakuan sehingga didapat Tabel 2 berikut ini

Tabel 2. Nilai Rata-Rata Sudut Belok Dengan IGBT Setiap Perlakuan

\begin{tabular}{|r|r|r|r|r|}
\hline \multirow{2}{*}{$\begin{array}{c}\text { Massa } \\
(\mathrm{kg})\end{array}$} & \multicolumn{4}{|c|}{ sudut } \\
\cline { 2 - 5 } & $0 \mathrm{~m} / \mathrm{s}$ & \multicolumn{1}{|c|}{$1 \mathrm{~m} / \mathrm{s}$} & \multicolumn{1}{l|}{$3 \mathrm{~m} / \mathrm{s}$} & $5 \mathrm{~m} / \mathrm{s}$ \\
\hline 48 & 2.83 & 11.82 & 9.92 & 10.64 \\
\hline 65 & 1.95 & 9.16 & 8.532 & 8.514 \\
\hline 82 & 1.52 & 2.616 & 1.948 & 2.986 \\
\hline 93 & 1.04 & 2.32 & 1.254 & 1.922 \\
\hline 108 & 1.07 & 0.958 & 1.092 & 1.868 \\
\hline
\end{tabular}

Setelah mendapat nilai rata-rata kemudian tabel ini dirubah ke bentuk grafik untuk 
mempermudah menjelaskan pengaruh penggunaan IGBT. Grafik akan ditampilkan sebagai berikut.

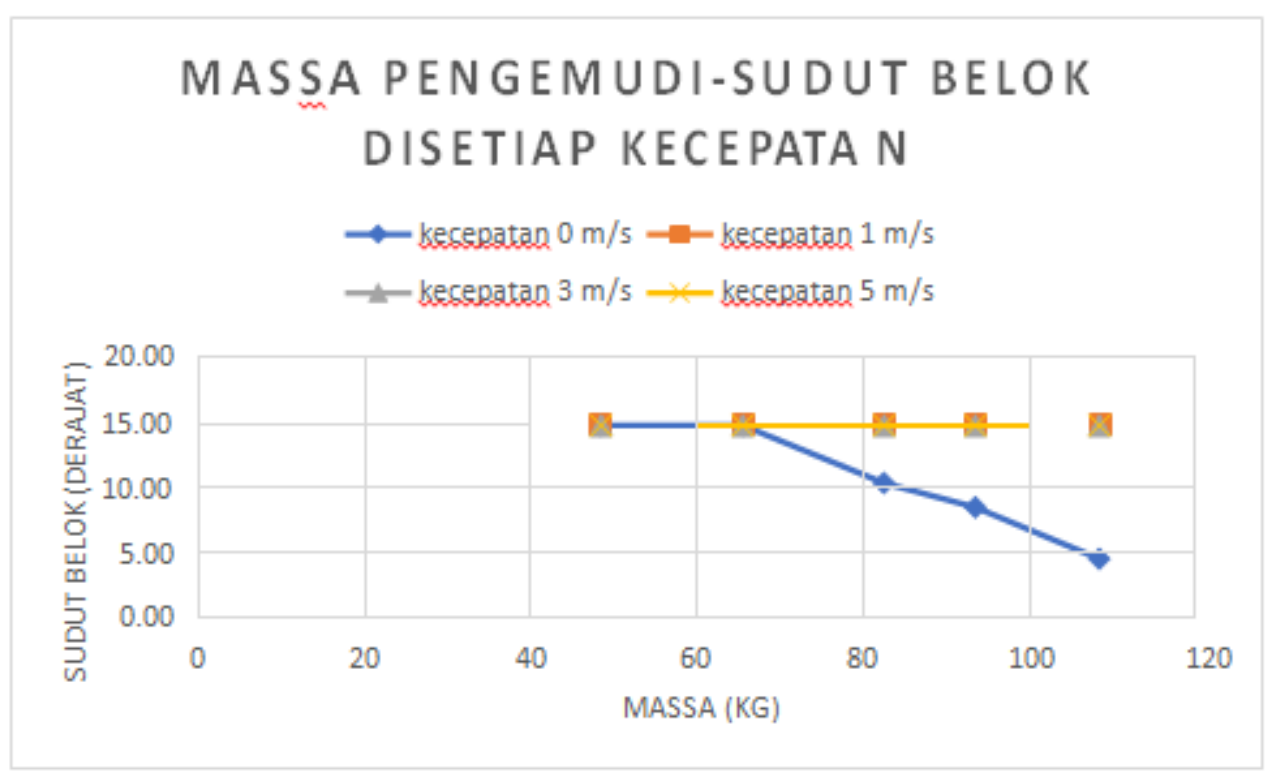

Gambar 1. Grafik Pembacaan Sudut Belok Dengan Driver IGBT

Pada Gambar 1 dapat dilihat bahwa sudut belok yang dihasilkan oleh motor DC sangat terpengaruh oleh kecepatan dan beban kendaraan. Hal ini disebabkan karena Tegangan driver H-bridge IGBT hanya menghasilkan tegangan sebesar $8.09 \mathrm{~V}$ ketika sistem kemudi diaktifkan. Tegangan $8.09 \mathrm{~V}$ yang dihasilkan ketika dilihat pada datasheet motor DC yang digunakan hanya akan menghasilkan max power sebesar < 45Watt. Akibat dari hal ini maka ketika mobil dibelokkan pada saat diam maka hambatan untuk membelok besar dan membuat mobil hanya berbelok sedikit saja. Ketika mobil bergerak dengan kecepatan rendah maka gaya gesek menjadi lebih sedikit karena gaya gesek statis selalu lebih besar dari gaya gesek kinetis. Tetapi ketika mobil bergerak dengan kecepatan $3 \mathrm{~m} / \mathrm{s}$ atau lebih gaya dorong dari belakang besar dan membuat motor tidak mampu berbelok dengan baik sehingga sudut belok di kecepatan $3 \mathrm{~m} / \mathrm{s}$ lebih kecil dibandingkan dengan sudut belok ketika kecepatan $1 \mathrm{~m} / \mathrm{s}$.

Sebagaimana cara menganalisis data dari driver IGBT pada analisis data pada driver MOSFET juga akan dilakukan rata-rata nilai pembacaan disetiap perlakuan dan kemudian dirubah menjadi grafik sehingga mudah untuk disimpulkan. Tabel rata-rata dan grafik akan ditampilkan berikut ini.

Tabel 3. Nilai Rata-Rata Sudut Belok Dengan MOSFET Setiap Perlakuan

\begin{tabular}{|r|r|r|r|r|}
\hline \multirow{2}{*}{$\begin{array}{c}\text { Massa } \\
(\mathrm{kg})\end{array}$} & \multicolumn{4}{|c|}{ Sudut } \\
\cline { 2 - 5 } & $0 \mathrm{~m} / \mathrm{s}$ & $1 \mathrm{~m} / \mathrm{s}$ & \multicolumn{3}{|c|}{$3 \mathrm{~m} / \mathrm{s}$} & $5 \mathrm{~m} / \mathrm{s}$ \\
\hline 48 & 14.67 & 14.67 & 14.67 & 14.67 \\
\hline 65 & 14.67 & 14.67 & 14.67 & 14.67 \\
\hline 82 & 10.27 & 14.67 & 14.67 & 14.67 \\
\hline 93 & 8.42 & 14.67 & 14.67 & 14.67 \\
\hline 108 & 4.48 & 14.67 & 14.67 & 14.67 \\
\hline
\end{tabular}




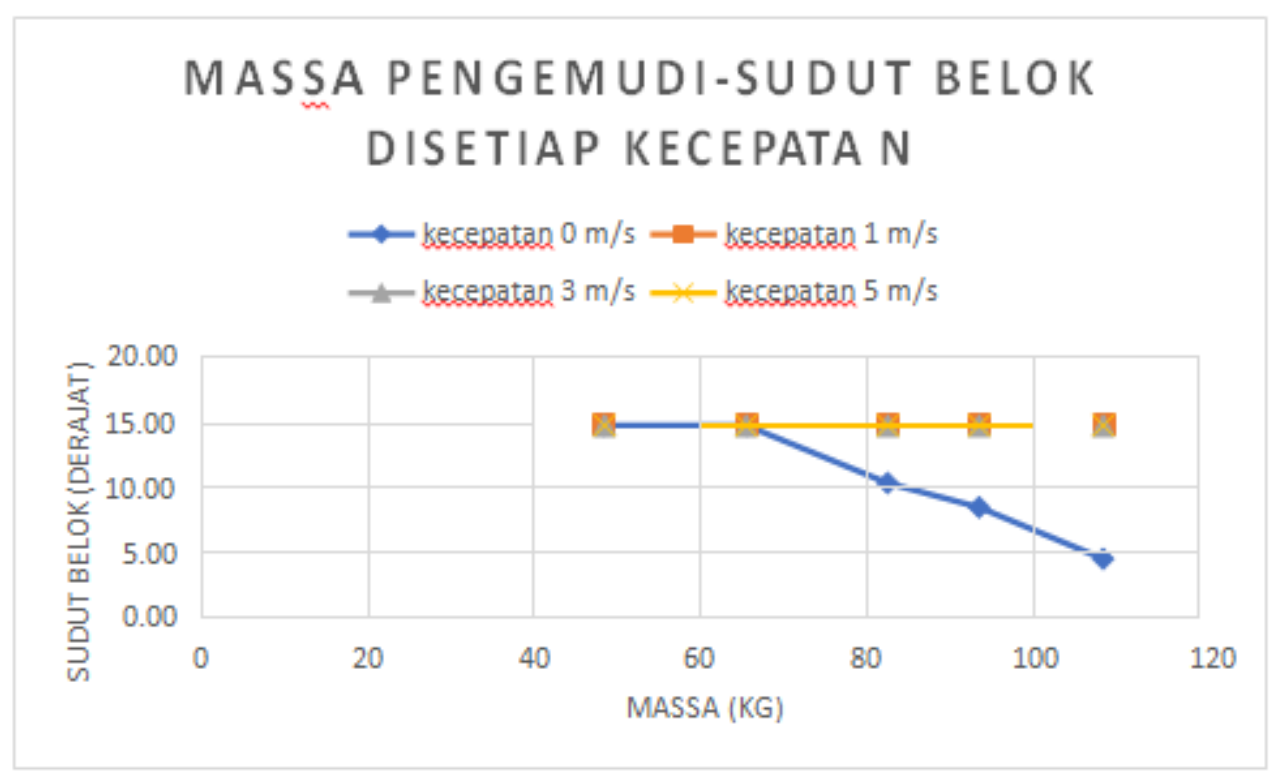

Gambar 2. Grafik Pembacaan Sudut Belok Dengan Driver MOSFET

Berbeda dengan driver IGBT yang sangat terpengaruh oleh massa pengemudi dan kecepatan kendaraan. Hasil pembacaan sudut belok menggunakan driver MOSFET cenderung stabil pada setiap kecepatan, tetapi ketika diam sudut belok terpengaruh oleh massa pengemudi. Hal ini disebabkan oleh gesekan yang meningkat ketika beban/massa pengemudi lebih besar. Akan tetapi ketika mobil berjalan sudut belok akan konsisten karena gesekan akan berkurang saat mobil berjalan sehingga mobil bisa menghasilkan sudut belok yang sama disetiap jenis massa pengemudi. Untuk menjawab rumusan masalah ini akan dilakukan uji t satu arah karena ini merupakan perbandingan nilai yang dianggap setara dan sama, dengan mengunakan data dari Tabel 1, alpha yang digunakan sebesar 0.05 sesuai dengan standard perbandingan didunia keteknikan dan hasil dari uji t adalah sebagai berikut.

Tabel 4. Uji T Dengan Microsoft Excel 2016

\begin{tabular}{|l|r|r|}
\hline \multicolumn{3}{|c|}{ t-Test: Two-Sample Assuming Equal Variances } \\
\hline & \multicolumn{1}{|c|}{ Mosfet } & \multicolumn{1}{|c|}{ IGBT } \\
\hline Mean & 13.6281 & 4.1983 \\
\hline Variance & 7.16249029 & 14.34113 \\
\hline Observations & 100 & 100 \\
\hline Pooled Variance & 10.7518088 & \\
\hline Hypothesized Mean Difference & 0 & \\
\hline df & 198 & \\
\hline $\mathrm{t}$ Stat & 20.3351189 & \\
\hline $\mathrm{P}(\mathrm{T}<=\mathrm{t})$ one-tail & $1.1255 \mathrm{E}-50$ & \\
\hline $\mathrm{t}$ Critical one-tail & 1.65258578 & \\
\hline $\mathrm{P}(\mathrm{T}<=\mathrm{t})$ two-tail & $2.2511 \mathrm{E}-50$ & \\
\hline $\mathrm{t}$ Critical two-tail & 1.97201748 & \\
\hline
\end{tabular}


Dari Tabel 4 nilai didapat $(\mathrm{t}<\alpha)$ 1.1255E-50 $<0.05$ sehingga H0 ditolak dan menerima $\mathrm{H} 1$ yaitu terdapat perbedaan sudut belok menggunakan driver IGBT dan MOSFET. Dari tabel ini juga menunjukan bahwa sudut belok menggunakan driver MOSFET jauh lebih besar jika dibandingkan dengan menggunakan driver IGBT. Hal ini bisa disebabkan karena tegangan yang dihasilkan oleh MOSFET lebih besar jika dibandingkan dengan IGBT pada saat pengetesan tegangan output $h$-bridge.

Merujuk dari hasil uji t diatas maka penelitian ini memperkuat jurnal yang dibuat oleh (Blake. 2001) bahwa Untuk tegangan lebih dari 300V IGBT lebig baik dari MOSFET tetapi sebaliknya MOSFET lebih baik dari IGBT ketika digunakan pada tegangan dibawah 300V. Masih merujuk pada hasil uji t Tabel 4 maka driver yang cocok digunakan sebagai pada sistem kemudi SBW adalah driver MOSFET tipe IRFP460.

\section{KESIMPULAN}

Pada penelitian ini disimpulkan bahwa driver h-bridge menggunakan MOSFET type IRFP460 lebih baik jika dibandingakn dengan menggunakan IGBT tipe FGL60N100BNTD dan menghasilkan sudut belok maksimal hampir disetiap kecepatan, dan terpengaruh beban lebih dari $65 \mathrm{Kg}$ saat kendaraan diam.

\section{DAFTAR PUSTAKA}

Blake, Carl dan Chris Bull. 2001. IGBT or MOSFET: Choose Wisely. International Rectifier

Fahami, Sheikh Muhammad Hafiz, Hairi Zamzuri, dan Saiful Amri Mazlan. 2015. Development of Estimation Force Feedback Torque Control Algorithm for Driver Steering Feel in Vehicle Steer By Wire System: Hardware in the Loop.International Journal of Vehicular Technology. ID 314597.

Fahami, Sheikh Muhammad Hafiz, Hairi Zamzuri, dan Saiful Amri Mazlan. 2014. The variable steering ratio for vehicle steer by wire system using hyperbolic tangent method. Applied Mechanics and Materials. vol.575. pp.781784.Kaufmann, Tim Scott Millsap, Brian Murray, dan Jim Petrowski. 2001. Development experience with steer by wire. in Proceedings of the SAE InternationalCongressandExhibition. SAE2001-01-2479.

Kumar, E. A., dkk. 2012. Anoverviewofactive front steering system. International Journal of Scientific \& Engineering Research, vol. 3, no.6.

Odenhtal, D., dkk. 2000. How to make steer-by-wire feel like power steering. In Proceedings of the15th IFAC WorldCongress Barcelona. Spain.

Shukla, N. K., dkk. 2017. Performance Evaluation of Three Phase Induction Motor Using MOSFET \& IGBT Based Voltage Source Inverter. International Research Journal of Engineering and Technology. Volune 04.

Yao, Yixin. 2006. Vehicle Steer-By-Wire System Control. SAE Technical Paper200601-1175. 
PENA TEKNIK: Jurnal Ilmiah Ilmu-Ilmu Teknik

Volume 3, Nomor 1, Maret 2018 : 73 - 80

Halaman ini sengaja dikosongkan 